\title{
Duplex Surface Treatment of an ARMCO Pure Iron by Dehydrated Paste-pack Boriding and Powder-pack Nitriding
}

\author{
O. A. Gómez-Vargas ${ }^{1}$, M. Ortiz-Domínguez ${ }^{2 *}$, J. Solis-Romero ${ }^{1}$, A. Arenas-Flores ${ }^{2}$, I. Morgado- \\ Gonzalez $^{2}$, J. Zuno-Silva ${ }^{2}$, F. R. Barrientos-Hernández ${ }^{2}$ and J. Medina-Marín ${ }^{2}$ \\ 1. Research and Postgraduate Division, Instituto Tecnológico de Tlalnepantla, EdoMéx, México. \\ 2. Department of Mechanical Engineering, Universidad Autónoma del Estado de Hidalgo-Campus \\ Sahagún, Hidalgo, México. \\ *Corresponding author:martin_ortiz@uaeh.edu.mx.edu
}

Wear is responsible for numerous industrial problems leading to increased maintenance costs due to the necessity of replacing worn components or due to equipment failure and manufacturing process downtime. Surface treatments can improve performance because the component maintains its ductile interior but with significantly improved surface wear resistance while using a minimal amount of material. Particularly, thermochemical boriding of iron alloys allows both single $\mathrm{Fe}_{2} \mathrm{~B}$ and FeB-based polyphases coatings to be obtained and then used mainly to improve surface hardness and wear resistance of the components for tribological applications. Likewise, nitriding is a thermochemical process that enriches the steel surface with nitrogen to enhance its mechanical and tribological properties. The secret of the nitriding process is that it does not require a phase change from ferrite to austenite, nor does it require a further change from austenite to martensite. In other words, the steel remains in the ferrite phase (or cementite, depending on alloy composition) during the complete procedure. The nitrided layer resulting from this thermochemical process comprises two sublayers: an outer compound layer and an underlying diffusion zone (layer). The compound layer is often composed of $\varepsilon-\mathrm{Fe}-2_{-3} \mathrm{~N}$ and $\gamma^{\prime}-\mathrm{Fe}_{4} \mathrm{~N}$ nitrides [1]. To mitigate the brittleness and those variations in microhardness, two multicomponent surface treatments such as boro-nitriding are being investigated. Nonetheless, very little work has been devoted to assess both the microstructural and mechanical characteristics of boron nitride coatings on ferrous materials [2]. In this study, the microstructure of the $\varepsilon-\mathrm{Fe}_{3} \mathrm{~N}, \mathrm{FeB}$, and $\mathrm{Fe}_{2} \mathrm{~B}$ layers formed on an ARMCO pure iron surface have been investigated at different temperatures by the powder-pack process. Cubic commercial samples were cut from an ARMCO iron bar. The substrate pure iron used in this work was selected to curb the effect of alloying elements in order to solely analyse the characteristic boride and nitride layers and some of their mechanical effects. The boro-nitriding treatment was carried out in two stages: boriding and then nitriding. Dehydrated paste-pack boriding and powder-pack nitriding procedures were preferred in this study for its cost-effectiveness, and simplicity of the required equipment. The samples were embedded in a closed in a closed cylindrical case (AISI 316L stainless steel) having a dehydrated paste of boron powder mixture inside with an average particle size of $10 \mu \mathrm{m}$. Boriding mixture contains of $\mathrm{B}_{4} \mathrm{C}$ (active source of boron), $\mathrm{Na}_{3} \mathrm{AlF}_{6}$ (activator), $\mathrm{SiC}$ (inert filler), and $\mathrm{SiC}_{8} \mathrm{H}_{20} \mathrm{O}_{4}$ which is used to protect surfaces. The powder-pack boriding process was carried out in a conventional furnace under a pure argon atmosphere at 1223 and $1273 \mathrm{~K}$ for $6 \mathrm{~h}$ of exposure for each temperature. Once the boriding treatment was finished the container was removed from the furnace and slowly cooled to room temperature. In the second step, the pre-boriding iron samples were nitrided by the pack method in the powder mixture consisting of calcium cyanamide $\left(\mathrm{CaCN}_{2}, \sim 24\right.$ wt.\% of $\left.\mathrm{N}\right)$ and calcium silicate $(\mathrm{CaSi}, \sim 35$ wt.\% of the mixture) as an activator. The samples were directly immersed in the powder mixture in another stainless steel cylindrical case. The nitriding temperatures were 773 and $843 \mathrm{~K}$ for $6 \mathrm{~h}$ using the same furnace and conditions. The samples were sanded with $\mathrm{SiC}$ papers and the polished with $6-\mu \mathrm{m}$ diamond paste to a mirror finish. The depth of 
the surface coatings and morphology were analysed by SEM and EDS (JEOL JSM-6360 LV). The distribution of alloying elements across the multicomponential coating was measured using the GDOES technique utilising a Horiba Jobin Yvon RF GD-Profiler $2^{\mathrm{TM}}$. X-Ray Diffraction (XRD) analyses of the layers were carried out with $2 \theta$ varying $20^{\circ}$ to $90^{\circ}$, using $\mathrm{CuK}_{\alpha}$ radiation and $\lambda=1.54 \AA$. Figure 1 shows the cross-sections and the EDS analysis obtained by SEM at the $\varepsilon-\mathrm{Fe}_{3} \mathrm{~N} / \mathrm{FeB}$ interphase for the borided ARMCO pure iron. The existence of the $\varepsilon-\mathrm{Fe}_{3} \mathrm{~N}, \mathrm{FeB}$ and $\mathrm{Fe}_{2} \mathrm{~B}$ were verified by X-ray diffraction (Fig. 2). The corresponding profile composition revealed maximum nitrogen content on the surface of 39.9 at $\% \mathrm{~N}$ (Fig. 3). Figure 4 shows the schematic representation of the GDOES sputtering and emission process [3]. These results demonstrate that the formed nitride layer exhibited a narrow transition zone between the nitride phase and the high hardness boride layer, which could be considered to favour the cohesion of the interface. The addition of a $\varepsilon-\mathrm{Fe}_{3} \mathrm{~N}$ coating on the boride layer is seen as a possibility of prevents the propagation of the corrosive medium to the substrate and the propagation of micro-cracks.

\section{References:}

[1] KH Habig, Mater. Eng. 2 (1980), p. 83.

[2] YA Balandin, Met. Sci. Heat Treat. 46 (2004), p. 385.

[3] GDOES Theory, https://www.spectruma.de/en/gdoes-theory.html (accessed February 9, 2019)

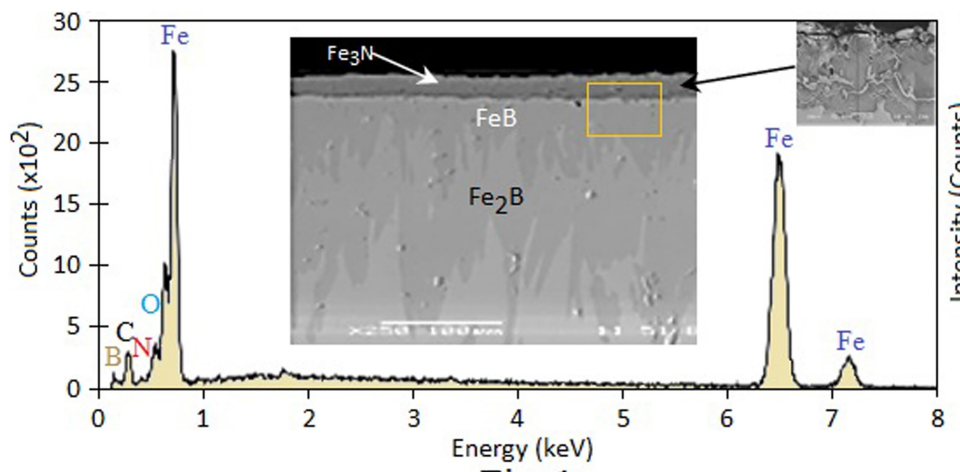

Fig. 1

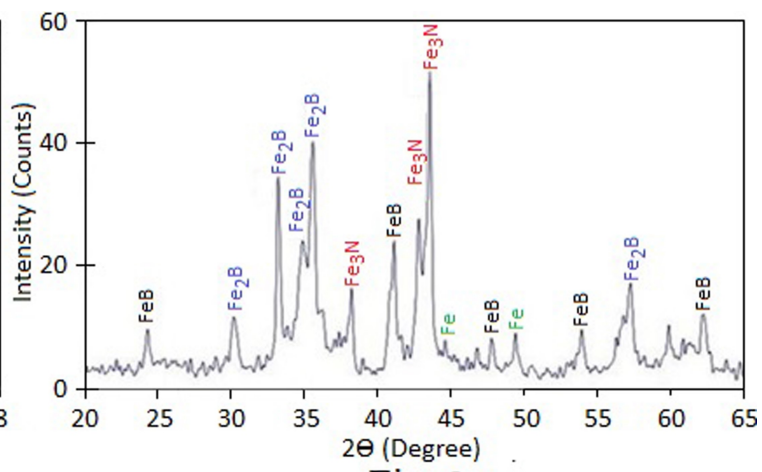

Fig. 2

Figure 1. Image (SEM) cross-sectional of boro-nitrided ARMCO pure iron showing the produced layers and Figure 2. X-ray diffraction patterns obtained at the surface of boro-nitrided pure iron exposed to the boriding conditions of $1273 \mathrm{~K}$ with $6 \mathrm{~h}$; and nitriding conditions of $843 \mathrm{~K}$ with $6 \mathrm{~h}$.

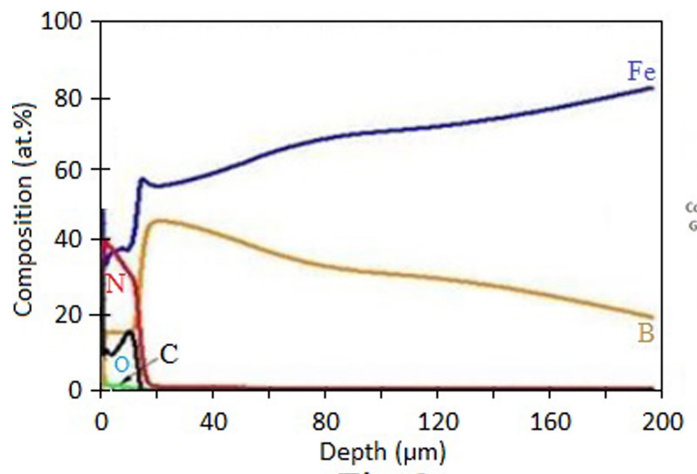

Fig. 3

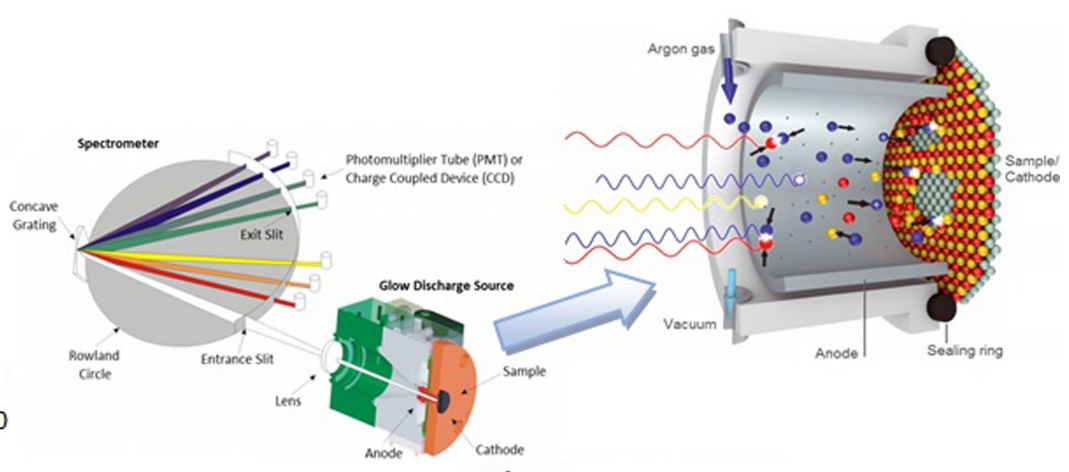

Fig. 4

Figure 3. GDOES spectrum of the elements distribution from the surface to the interior of the nitride ( $\varepsilon$ $\mathrm{Fe}_{3} \mathrm{~N}$ ) at $843 \mathrm{~K}$ with $6 \mathrm{~h}$, and boride ( $\mathrm{FeB}$ and $\mathrm{Fe}{ }_{2} \mathrm{~B}$ ) layers at $1273 \mathrm{~K}$ with $6 \mathrm{~h}$ and Figure 4. schematic representation of the GDOES sputtering and emission process. 